\title{
O ESTÁGIO CURRICULAR NA UNIVERSIDADE DO ESTADO DO PARÁ CAMPUS VII ULTRAPASSANDO A CONCEPÇÃO TÉCNICO-APLICACIONISTA: LIMITES E POSSIBILIDADES
}

\author{
Nívea Mํㅡㄹ Coelho Barbosa de Almeida ${ }^{1}$ \\ Darlene Araújo Gomes² \\ Nidal Afif Obeid Freitas ${ }^{3}$ \\ Walnélia Benigno Magalhães Carrijo ${ }^{4}$
}

\section{INTRODUÇÃO}

O Estágio Curricular Obrigatório, tem provocado críticas, reflexões e tímidos avanços nos meios acadêmicos. Tentativas de superação da dicotomia teoria-prática são insipientes, mudanças de rota, urgentes. Muitas são as tentativas de superação da dicotomia teoria-prática. Porém, práticas arraigadas e Projetos Políticos dos Cursos de Formação desarticulados das demandas contemporâneas, tem se constituído em entraves para as mudanças almejadas.

Historicamente, o Estágio Curricular obrigatório tem se constituído em momento estanque, separado da teoria adquirida na academia - polo prático da formação -. Subjaz a ideia de que antes se deve instrumentalizar os discentes para, posteriormente, aplicar a teoria na prática.

Assim, o objetivo principal dessa pesquisa consistiu em apresentar as mudanças ocorridas na concepção do estágio na referida universidade, este, como elo integrador entre as disciplina do currículo, bem como apontar novas perspectivas para o orientação e realização do mesmo centrada na formação prática, estabelecendo conexões com a teoria que a embase em articulação com todas as disciplinas do currículo.

O interesse em pesquisar a metodologia desenvolvida no estágio supervisionado, se deu em função de nossa atuação como docentes dessa ${ }^{1}$ disciplina nas turmas finais do curso de Pedagogia e por ter acompanhado as ações desenvolvidas no lócus do estágio. As atividades ali desenvolvidas consistiam

\footnotetext{
1 'Docente da Universidade do Estado do Pará niveamjulia@yahoo.com.br

2 Técnica em Educação 15a URE lenegomes20@yahoo.com.br

3 Doutoranda do Programa de Pós-Graduação Educação para a Ciência, Universidade Estadual Paulista - Campus de Bauru, São Paulo. nidalfreitas@yahoo.com.br

4Assessora Pedagógica da UEPA walnelia@yahoo.com.br
} 
basicamente em atividades de observação e regência, além de preenchimentos infindáveis de fichas, como também, elaborações de relatórios ao final do estágio. Esse, sem nenhuma reflexão mais aprofundada sobre a realidade da escola e as questões do contexto que permeiam toda prática educativa.

Estas inquietações nos fizeram refletir sobre nossa própria prática como docentes e/ou técnicos dos cursos analisados, também sobre os documentos orientadores emanados pela universidade e sobretudo, sobre as discussões que estão sendo tratadas no contexto educacional brasileiro a respeito dessa disciplina.

Encontramos nessa investigação, uma oportunidade de refletirmos sobre nossas práticas relacionando-as às exigências profissionais contemporâneas e ao perfil do egresso que pretendemos formar.

Para tanto, faz-se necessário que concebamos a relação teoria-prática como indissociáveis, que neguemos a dicotomia existente entre elas e adotemos uma visão de unidade como relação simultânea e recíproca.

Nessa linha de raciocínio, há que se considerar que, a dimensão prática deve ser considerada na formação inicial do professor, não como imitação de modelos, reprodução de posturas, como ocorre historicamente, mas como possibilidade de se estabelecer conexões entre a teoria e a realidade onde se desenvolverá essa prática. Na perspectiva de uma relação dialética.

Nesse sentido, objetivamos apresentar mudanças ocorridas na concepção do Estágio na Universidade Estadual do Pará, na perspectiva deste como elo integrador entre as disciplinas do currículo e como pesquisa que se aproxima da prática de forma reflexiva.

As novas exigências da sociedade em transformação tem requerido da educação formal, novas posturas frente o currículo formativo dos profissionais que atuarão na escola e fora dela, nos contextos sociais. Disciplinas como Didática e Práticas de Ensino constituem-se referências dentro do currículo formativo desses cursos, por possibilitarem o aprofundamento da temática no sentido de se desconstruir a concepção de estágio como a parte prática do curso, sem conexão com as outras disciplinas.

Partindo da premissa de que a dimensão prática deve ser considerada na formação inicial do professor, mas que historicamente essa prática tem se constituído em atividades de imitação de modelos, reprodução de posturas, sem uma reflexão crítica, esta a luz de uma fundamentação teórica que a embase, 
buscamos desenvolver um trabalho com os discentes do sétimo e oitavo períodos do Curso de Pedagogia da Universidade do Estado do Pará, na tentativa de inserir, os futuros professores no contexto educativo, estes com perfil diferenciado: o de professor pesquisador de sua prática. Assim, aguçar o olhar desse formando para que o mesmo enxergue e veja a realidade na qual irá atuar, como fonte de possibilidades de intervenção no sentido de transformá-la, é o nosso propósito.

Inicialmente fizemos o levantamento de todas os relatórios e fichas preenchidos pelos alunos a fim de analisar a relação entre a teoria abordada nas disciplinas do currículo e as atividades desenvolvidas no campo do estágio, na perspectiva de encontrar apontamentos que indicassem uma visão da totalidade pelos discentes.

Nesse contexto, o presente trabalho visa relatar os resultados de uma pesquisa desenvolvida com os alunos concluintes do Curso de Pedagogia da referida Universidade, no período de 2013, 2014 e 2015.

Em síntese, o olhar que se desejou adotar no decorrer da pesquisa requereu de todos nós, docentes e/ou técnicos que atuam nessas turmas, um olhar de quem olha de fora, de pesquisador, com o distanciamento que a pesquisa requer, deixando de lado, ainda que momentaneamente, a roupagem de docentes daquelas turmas. Para que o distanciamento necessário nos possibilitasse ver que as mudanças se fazem necessárias, visão do Estágio como espaço de formação, que ultrapasse os modelos aplicacionistas e assumam a concepção dialética, a qual possibilitará compreender a teoria e a prática, não como polos distintos, mas como elementos de uma relação que proporcione buscas teóricas a partir das reflexões sobre a prática.

\section{PERCURSO METODOLÓGICO DA PESQUISA}

A pesquisa baseou-se em análise dos relatórios e fichas de estágio das turmas do curso de Pedagogia da Universidade do Estado do Pará, nos anos de 2013, 2014 e 2015.

A pesquisa utilizada foi do tipo: exploratório-explicativa e abordagem quanti-qualitativa. Buscou-se elementos que revelassem o estágio no contexto da formação dos futuros professores e o elo de ligação entre este, a teoria ambos 
conectados à realidade. Os sujeitos foram os alunos concluintes do curso de Pedagogia.

Inicialmente realizamos o levantamento de todas os relatórios e fichas preenchidos pelos alunos, a fim de analisar nas anotações dos alunos, a relação estabelecida entre a teoria abordada nas disciplinas do currículo, e as atividades desenvolvidas no campo do estágio, na perspectiva de encontrar apontamentos que indicassem uma visão de totalidade por parte dos discentes, como também pistas que nos indicassem a existência de relação entre teoria e prática e se havia articulação entre as atividades desenvolvidas com as demais disciplinas do currículo.

Na etapa seguinte, realizamos a tabulação dos dados que nos permitiram constatar os entraves e avanços do estágio supervisionado na universidade pesquisada.

\section{A Importância do Estágio na Formação Docente}

No movimento teórico recente sobre a concepção de estágio, é possível perceber que significativas mudanças estão ocorrendo quanto a forma de se conceber essa disciplina no processo formativo do aluno. Pimenta e Gonçalves(1990) consideram que a finalidade do estágio é propiciar a aproximação do aluno à realidade na qual irá atuar.

Almeida e Pimenta (2014) concebem o estágio como um campo de conhecimento que envolve estudos, análise, problematização, reflexão e proposição de soluções para o ensinar e o aprender.

Pimenta (2001) advoga que o estágio deve ser desenvolvido ao longo de toda trajetória do curso, sendo assim, todas as disciplinas podem oferecer seus aportes teóricos para a construção nessa formação.

No que concerne à primeira consideração, devemos destacar que não só no momento do estágio o discente deverá se aproximar do seu futuro lócus de atuação, visto que, toda disciplina tem sua parte prática, a qual deveria ser melhor utilizada pelo corpo docente.

No que concerne à segunda consideração, Almeida e Pimenta concebem o estágio como atividade dinâmica, reflexiva e de resultados para o discente -futuro mestre e para a escola ou outra instituição campo de atuação desses. Rompe-se 
com a ideia de estágio como mero cumprimento de carga-horária para integralização do curso, ou como atividade burocrática, ou como mera imitação de modelos, para assumir uma postura investigativa e comprometida com os problemas e demais situações observadas.

Na terceira consideração, Pimenta (2001), ao defender o estágio desde o início do curso, apresenta essa disciplina como elemento articulador do currículo e não um apêndice, desarticulado das demais disciplinas que compõem o processo formativo do educando.

Nesse sentido, evidencia-se a concepção de estágio como elo integrador entre as disciplinas que pode favorecer a construção dialética do conhecimento.

\section{O ESTÁGIO SUPERVISIONADO NO PROJETO POLÍTICO PEDAGÓGICO DA UEPA}

Encontramos no referido documento legal, apontamentos a respeito do percurso formativo dos discentes do Curso de Pedagogia, cujos princípios norteadores são: princípio da indissociabilidade entre teoria e prática; flexibilidade curricular; princípio da pesquisa; princípio da interdisciplinaridade. A aplicação desses conceitos possibilitam a ressignificação das práticas, ajudam a reduzir as distâncias entre o saber e o saber fazer.

Quanto à forma de realização do estágio curricular na referida universidade, o PPP reza que o mesmo deverá ser realizado ao longo do curso, oportunizando atividades desde a Educação Infantil, as séries iniciais do Ensino Fundamental, da Educação Profissional, na Educação de Jovens e Adultos, grupos de reforço, na gestão e também em ambientes não escolares.

Contudo, no desenho curricular do curso em análise, o estágio curricular figura nos dois últimos semestres do curso.

Assim, segundo este documento, o objetivo principal da disciplina Estágio Supervisionado, é: "contribuir para um maior aprofundamento teórico-prático do alunos do curso de Pedagogia. (UEPA, 2006, S/P).

Podemos dizer que o estágio ocorre em tempo e espaço curricular específico, e que a intensão da instituição universitária é que a dimensão prática transcenda o estágio tendo como finalidade promover a articulação das diferentes práticas. 


\section{RESULTADOS E DISCUSSÃO}

Dos resultados obtidos na pesquisa foi possível constatar que existem duas situações a serem consideradas. A primeira diz respeito aos dois primeiros anos analisados; 2013 e 2014, no que se refere a esses estágios, quase a totalidade dos discentes relataram em seus relatórios que a disciplina Estágio praticado na Universidade, tem se constituído em momento estanque ao vivenciado na sala de aula e que o mesmo ocorre como mera formalidade de cumprimento de carga-horária, preenchimento de intermináveis fichas, relatórios, como também atividades de auxiliar nos trabalhos das instituições, lócus do estágio, sem nenhuma relação com a teoria assumida nas disciplinas do currículo.

Já na turma concluinte de 2015, constatou-se mudanças quanto ao desenvolvimento dessa disciplina; observou-se que as fichas e o relatórios já não mais se constituíam em instrumentos burocráticos e desconexos, todas as ações eram refletidas, analisadas, contextualizadas. Verificou-se também que a partir do referido ano, os alunos eram requeridos a produzirem artigos científicos a partir dos resultados das pesquisas realizadas no campo do estágio. Assim, os resultados a que tivemos acesso, estão explicitados da seguinte forma:

No Estágio em Gestão, 40\% dos egressos relataram que a vivência no referido estágio os possibilitou conhecer um pouco a rotina da escola, 30\% relataram que as atividades referentes ao trabalho do gestor que vivenciaram foram insignificantes e não contemplaram suas expectativas com relação ao estágio e 30\% concluíram que o tempo destinado ao estágio foi insuficiente para a apreensão dos conhecimentos sobre a gestão.

No Estágio em Instituições Não-Escolares e Ambientes Populares, 80\% dos alunos relataram que o estágio não proporcionou os conhecimentos almejados para atuarem nesses espaços e os outro $20 \%$ comentaram que além do tempo ser exíguo, a carga-horária da disciplina que embasa esse estágio é reduzida, não possibilitando um conhecimento mais amplo sobre esses espaços.

Já no Estágio nas Séries Iniciais do Ensino Fundamental, com uma cargahorária de quatrocentas horas, divididas em duas etapas: Educação Infantil e $1^{\circ}$ ao 5o Ano, $100 \%$ dos alunos alegaram que o estágio no final do curso, não os 
possibilitou uma reflexão à luz das teorias. Discorreram que a realidade é muito diferente do que se discute na academia e metade deles se disseram chocados com o que vivenciaram. Desses, $70 \%$ afirmam não pretenderem atuar na sala de aula.

Ressalta-se que na referida universidade, os responsáveis pela organização dessa disciplina, têm buscado promover modificações no perfil do estágio, através de introdução de novas metodologias, como: a orientação de que a referida disciplina ocorra em consonância às outras do Currículo. Que a disciplina Didática auxilie nessa reflexão crítica e dialética (ação-reflexão-ação) sobre a realidade e que a partir de 2015 todos os estágios tenham como uma das ações a serem desenvolvidas nas instituições, a elaboração e execução de projetos de intervenção, a partir das análises e reflexões sobre a realidade e necessidades local. Também foi instituído o momento de socialização das práticas desenvolvidas nos estágios, através de comunicação oral, painel, pôster seminários e outros, no final de cada semestre letivo, além da exigência de elaboração de artigos científicos, a respeito das experiências vivenciadas nessa etapa formativa de sua escolaridade.

\section{CONSIDERAÇÕES FINAIS}

O estudo possibilitou conhecer as nuances assumidas no Estágio Curricular, analisar seu desenvolvimento bem como os avanços ocorridos.

Das conclusões do estudo podemos nos arriscar a dizer que a referida disciplina, desenvolvida no Campus VII, nos anos de 2013 e 2014 ainda apresentava os ranços de uma metodologia voltada para a imitação de modelos, práticas burocratizadas como: preenchimentos de fichas, organização de arquivos nas escolas. Já no ano de 2015, essa disciplina assumiu uma concepção críticoinvestigativa, onde os discentes foram induzidos a apresentar propostas de intervenções nos locais de realização dos estágios a partir das necessidades observadas. Como forma de superação de práticas ultrapassadas. Além de socialização dos resultados da pesquisa para toda comunidade acadêmica e extraescolar.

A evidência do desenvolvimento do estágio apenas nos dois últimos semestres do curso, na nossa concepção esbarra nas concepções de estágio adotada pela Instituição Formadora, que preconiza o estágio como elo integrador 
entre as disciplinas, impossibilitando a sua integração no corpo de conhecimento do curso de formação.

Dessa forma, propomos a reorientação do Estágio, que embora não descarte as antigas formas de desenvolvimento, desenvolva atividades que possibilitem aos alunos aprofundarem conhecimentos referentes ao futuro campo de trabalho, através de um olhar crítico-investigativo-reflexivo e que todos os professores e orientadores do estágio, se envolvam no processo como responsáveis e colaboradores.

\section{REFERÊNCIAS}

ARANDA, M. A. M; NASCIMENTO, M. J. O. Estágio Supervisionado na gestão e na docência em Pedagogia: inquietações e mudanças ao compasso da legislação e da sensibilidade. In.: GONÇALVES, A. V et al (orgs). Estágio Supervisionado e Práticas Educativas: Diálogos interdisciplinares. Dourados (MS): Editora UEMS, 2011. p. 229-254.

BORTONI-RICARDO, S. M. O professor pesquisador: Introdução à pesquisa qualitativa. São Paulo: Parábola Editorial, 2008.

CRISTÓVÃO, V. L. L. Parcerias no desenvolvimento profissional do professor: espaço de (re)significação para o Estágio Supervisionado. In.: GONÇALVES, A. V. et al

(orgs).

Estágio Supervisionado e Práticas Educativas: Diálogos interdisciplinares. Dourados (MS): Editora UEMS, 2011. p. 145-158.

FAZENDA, I. Interdisciplinaridade: visões culturais e epistemológicas. In.: FAZENDA, I. O que é Interdisciplinaridade?. São Paulo: Editora Cortez, 2008. p. 17-28.

FONTANA, R. A. C. Estágio: do labirinto aos frágeis Fios de Ariadne. In.: GONÇALVES, A. V. et al (orgs). Estágio Supervisionado e Práticas Educativas: Diálogos interdisciplinares. Dourados (MS): Editora UEMS, 2011. p. 19-32.

GONÇALVES, A. V. Estágio Supervisionado em Letras: teoria nos documentos de estágio. In.: GONÇALVES, A. V et al (orgs). Estágio Supervisionado e PráticasEducativas: Diálogos interdisciplinares. Dourados (MS): Editora UEMS, 2011. p. 207- 228.

LAKATOS, E. M.; MARCONI, M. A. Fundamentos da Metodologia Científica. 5 ed. São Paulo: Atlas, 2003.

LOPES, M. A. P. T. Estágio Supervisionado: diálogos possíveis entre a instância formadora e a escola. In.: GONÇALVES, A. V. et al (orgs). Estágio Supervisionado 
e Práticas Educativas: Diálogos interdisciplinares. Dourados (MS): Editora UEMS, 2011. p. 159-180.

LÜDKE, M; BOING, L. A. Do trabalho à formação de professores. Cadernos de Pesquisa. Maio/Agosto, 2012. № 146, v. 42, p. 428-451.

MESQUITA, N. A. S.; SOARES, M. H. F. B. A formação pela pesquisa: o estágio como espaço de construção dos saberes. In.: GONÇALVES, A. V. et al (orgs). Estágio Supervisionado e Práticas Educativas: Diálogos interdisciplinares. Dourados (MS): Editora UEMS, 2011. p. $291-306$.

PAQUAY, Léopold.; PERRENOUD, Fhilippe.; ALTET, Marguerite.; CHARLIER, Évelyne (org). Formando Professores Profissionais Quais Estratégias? Quais Competências? 2 ed. Porto Alegre - RS: Artmed, 2001.

PIMENTA, Sema G. O Estágio na Formação de Professores - Unidade Teoria e prática? 9 ed. São Paulo- SP: Cortez, 2010.

PIMENTA, S. G.; ANASTASIOU, L. G. C. Docência no Ensino Superior. $4^{a}$ ed. São Paulo: Cortez, 2010. PIMENTA, S. G.; LIMA, M. S. L. Estágio e Docência: diferentes concepções. In.:

PIMENTA, Selma G.; LIMA, Maria S. L. Estágio e Docência. 5 ed. São Paulo-SP: Cortez, 2010.

SILVA, W. R.; BARBOSA, S. M. A. D. Desafios do Estágio Supervisionado numa licenciatura dupla: flagrando demandas e conflitos. In.: GONÇALVES, A. V. et al (org.). Estágio Supervisionado e Práticas Educativas: Diálogos interdisciplinares. Dourados (MS): Editora UEMS, 2011. p. 181 -206.

SILVA, W. R. Construção da interdisciplinaridade no espaço complexo de ensino e pesquisa. Cadernos de Pesquisa. Maio/Agosto, 2011. № 143, v. 41, p. 582-605.

SILVA, W. R. Reflexão pela escrita no estágio supervisionado da licenciatura: Pesquisa em linguística aplicada. 2014 (no prelo). 